\title{
INTERSEÇÕES TEÓRICO- METODOLOGICAS ENTRE A HISTÓRIA DO ENSINO E A HISTÓRIA DA MATE MÁTICA: discutindo a pesquisa sobre o movimento da matemática moderna
}

\author{
M odern mathematics movement: intersections between \\ history of teaching and history of mathematics
}

\begin{abstract}
André Luís Mattedi Dias
Professor adjunto B da Universidade Estadual de Feira de Santana, Feira de Santana, Bahia - Brasil, e-mail: mattedi@uefs.br
\end{abstract}

\begin{abstract}
Resumo
A presento um argumento em favor da aproximação teóricometodológica da história do ensino da matemática com a história da matemática, fundamentado na existência de uma interseção entre os processos históricos que resultaram naquilo que se convencionou chamar de Movimento da Matemática Moderna, por um lado, e um outro processo de expansão da influência científica e matemática norte-americana na América Latina, a saber, a presença do matemático americano Marshall Stone, protagonista dos dois casos. Concluo defendendo a tentativa de construção de um quadro teórico-metodológico apropriado para efetivar essa aproximação nas pesquisas históricas dos dois campos, mas trago uma restrição à utilização do conceito de cultura e da metodologia da descrição densa de Clifford G eertz
\end{abstract}

Rev. D iálogo Educ., Curitiba, v. 9, n. 26, p. 61-79, jan./ abr. 2009 
concomitante com a abordagem da história cultural tal como proposta por Roger Chartier, em virtude das críticas que o próprio Chartier faz à utilização dos elementos de G eertz.

Palavras-chave: Movimento da matemática moderna. História do ensino da matemática. História da matemática.

\begin{abstract}
I present an argument for theoretical and methodological approximation between history of mathematical teaching and history of mathematics, based on an intersection between the historical processes that resulted on the so called Modern Mathematical Movement, for one hand, and another historical process that increased north American scientific and mathematical influence over Latin American, that is, the presence of north American mathematician Marshall Stone as protagonist of both processes. I conclude arguing for the production of an appropriate framework for research in this fields, although it should be necessary a restriction against the connection of Geertz's concepts of culture and thick description ethnographic method with Chartier's cultural history concepts and methods, because of Chartier's criticisms of Geertz's ethnographic point of view.
\end{abstract}

Keywords: Modern mathematics movement. History of mathematics teaching. History of mathematics.

\title{
Marshall Stone e o movimento da matemática moderna
}

Uma equipe de brasileiros e portugueses retomou em 20050 interesse pelo Movimento da Matemática Moderna (MMM) e vem realizando estudos históricos comparativos entre Brasil e Portugal no âmbito da sua recepção nas práticas pedagógicas do ensino da disciplina nos dois países (MATO S; VALENTE, 2007; REVISTA DIÁLOGO EDUCACIONAL, 2006; inspirados num projeto internacional mais amplo que realizou trabalho semelhante para os casos de alguns países europeus e dos EUA (BELHOSTE; G ISPERT; HULIN, 2006).

Segundo os próprios pesquisadores brasileiros e portugueses (MATO S; VALENTE, 2007), estes estudos inserem-se na área emergente da

Rev. Diálogo Educ., Curitiba, v. 9, n. 26, p. 61-79, jan./ abr. 2009 
Interseções teórico-metodológicas entre a história do ensino e a história da matemática

história do ensino da matemática, cujos especialistas vêem organizando os seus primeiros fóruns nacionais e internacionais, seus primeiros congressos e publicações, onde estão sendo discutidas abordagens e metodologias em colaboração com especialistas da história da matemática e da história da educação. ${ }^{1}$

Tentarei argumentar neste trabalho que a reivindicação de proximidade teórica e metodológica entre a história do ensino da matemática e a história da matemática não é neste caso algo arbitrário ou a priori, mas sustenta-se na existência de elementos comuns nos próprios processos históricos, num caso e no outro.

A historiografia da matemática registra uma série de inovações, modificações e transformações ocorridas ao longo do século XIX em diversos aspectos constitutivos da matemática, em importantes centros científicos, principalmente França e Alemanha (BOS; MEHRTENS; SCHNEIDER, 1981; BALDINO, 1994; SCHUBRING, 2000; SCHUBRING, 2001; GRAY, 2004; ROWE, 2004). Sua institucionalização em âmbito mundial se concretizou, dentre outras formas, em programas internacionais de reforma e atualização do ensino nos diversos níveis dos sistemas escolares de vários países.

De fato, o primeiro movimento internacional para reforma dos programas de ensino secundário da matemática foi constituído oficialmente em 1908, durante o IV Congresso Internacional de Matemáticos, realizado em Roma, quando foi criada a Comissão Internacional de Ensino da Matemática (C omission Internationale de l'E nseignement Mathématique - CIEM), presidida pelo alemão Felix Klein e pelo americano D avid Eugene Smith (SCHUBRING, 1999; BRAGA, 2003).

Depois da Segunda Guerra, em 1952, a CIEM foi revitalizada e renomeada como ICMI (International Commission on Mathematical Instruction) no contexto da reorganização da International Mathematical U nion (IMU), presidida pelo norte-americano Marshall H. Stone (1903-1989). Nesse mesmo período, em 1950, foi criada a Comission Internationale pour l'E tude et l'A melioration del'E nseignement de Mathématiques (CIEAEM), que reunia especialistas como Jean Piaget, Jean Dieudonné e Caleb Gategno, e pretendia coordenar trabalhos realizados por profissionais de diferentes formações e nacionalidades (FELIX, 1986; D’AMBRO SIO, 1987 ; BÚRIG O, 1989).

Porém, considera-se normalmente a sessão de estudos dedicada à reforma do ensino da matemática realizada em 1959 em Royaumont, França, organizada pela Organização Europeia de Cooperação Econômica (OECE), financiada pelo Plano Marshall, como o principal marco referencial do segundo movimento internacional de reorganização e atualização dos currículos escolares para o ensino da matemática, conhecido como Movimento da Matemática Moderna (MMM) (GUIMARÃES, 2007). Participaram desta sessão representantes de 16

1 International Journal for the History of Mathematics Education . Disponível em: <http:/ / www.tc.columbia.edu/ centers/ ijhmt/ >. Acesso em: 13 fev. 2009.

Rev. D iálogo Educ., Curitiba, v. 9, n. 26, p. 61-79, jan./ abr. 2009 
países europeus, mais Canadáe EUA, entre matemáticos, professores de matemática universitários ou do ensino secundário, que deveriam "se consagrer a l'élaboration d'un programme d'enseignement rationnel et onforme aux conœeptions nouvelles des mathématiques, sans se laisser influencer par les programmes en vigueur ni par la situation présente." Os participantes ficariam divididos em três seções de trabalho, que tratariam dos seguintes temas: novas concepções no domínio das matemáticas; novas concepções de ensino das matemáticas e execução da reforma. Esta sessão de estudos de Royaumont foi presidida por Marshall Stone (OECE, 1961, A vant-propos).

Um dos principais e mais imediatos resultados desta sessão de estudos foi a publicação, em 1961, do livro U m programme moderne de mathématiques par l'enseignement secondaire, elaborado por uma comissão de especialistas reunidos pela OECE em Dubrovnik, em 1960, que seguiu as recomendações de Royaumont no sentido de estabelecer as bases da reforma pretendida (GUIMARÃES, 2007, p. 22). As repercussões desse programa não ficaram restritas aos países europeus, aos EUA e ao Canadá, mas irradiaram-se por outros países e outras regiões, em particular, tiveram fortes repercussões para a América Latina e para o Brasil.

0 destaque para Marshall Stone neste caso não é meramente apologético, mas estratégico para as nossas pretensões de justificar em certas bases a proximidade teórico-metodológica entre a história do ensino da matemática e a história da matemática, como mostrarei a seguir.

\section{Marshall Stone e a expansão da influência científica Americana}

Marshall Stone iniciou seus estudos na Universidade de Harvard em 1922, onde obteve seu doutorado em 1926, sob a orientação de G eorge D avid Birkhoff (1884-1944), que influenciou bastante o início da sua carreira matemática, desenvolvida principalmente em Harvard. D urante a II Guerra, Stone realizou trabalhos secretos para o Escritório de O perações Navais e para o Departamento de Guerra dos EUA. Após a guerra, assumiu a chefia do Departamento de Matemática da Universidade de Chicago, segundo ele, motivado pela convicção de que era o tempo para uma "fundamental revision of graduate and undergraduate mathematical education." (STO NE, 1989, apud O'CO NNOR; ROBERT SO N).

Foi neste mesmo período da Segunda Guerra Mundial, que Stone associou-se novamente com Birkhoff, desta vez na tarefa de expandir a influência da matemática norte-americana para a América Latina. De acordo com Ortiz (2003a, 2003b), Birkhoff realizou uma longa visita à América Latina em 1942, com o objetivo de aproximar os matemáticos da região com as linhas de pesquisa que desenvolvia. Esta visita era parte de um dos programas da política expansionista

Rev. Diálogo Educ., Curitiba, v. 9, n. 26, p. 61-79, jan./ abr. 2009 
Interseções teórico-metodológicas entre a história do ensino e a história da matemática

norte-americana para a A mérica Latina, formulada na "política de boa vizinhança" do presidente Franklin D. Roosevelt, que ampliou o intercâmbio com a região para o âmbito cultural e científico, pois os estrategistas norte-americanos consideravam a ciência e a tecnologia como componentes essenciais de um plano de segurança para os interesses do EUA no hemisfério sul. Roosevelt convidou Nelson Rockefeller, jovem político da elite industrial e financeira norte-americana, ligado obviamente à Fundação Rockefeller, para chefiar 00 ffice for C oordination of $\mathrm{E}$ conomic and Cultural Relations between the A merican Republics, ${ }^{2}$ que trouxe Henry Allen Moe (1894-1975), secretário da Fundação G uggenheim, para dirigir a seção dos intercâmbios culturais, que manteve um programa de bolsas para jovens intelectuais latino-americanos em universidades norte-americanas, um dos fatores para a formação e manutenção de um "invisible college" de intelectuais que atuou decisivamente para a expansão da influência científica norte-americana na região.

Ortiz salienta que uma das consequências da visita de Birkhoff à Argentina foi o reconhecimento que tiveram as linhas de pesquisa do seu grupo, voltadas para os temas abstratos da análise matemática moderna, "siguiendo orientaciones que habían ontribuido a elaborar algunos de sus disápulos en la escuela de $\mathrm{H}$ arvard, particularmente Stone."

A historiografia da matemática no Brasil menciona a presença dos matemáticos norte-americanos Adrian Albert (1945), Marshall Stone (1945) e Warren Ambrose (1945) no Brasil neste período, embora ainda não faça qualquer relação explícita - muito provável - com aquele programa expansionista. D e fato, Marshall Stone ministrou um curso sobre anéis de funções contínuas na Faculdade Nacional de Filosofia (FNFi) do Rio de Janeiro, quando conheceu Leopoldo Nachbin, Maurício Matos Peixoto, Marília Chaves Peixoto e Maria Laura Mousinho, jovens e promissores matemáticos brasileiros, que foram contemplados com bolsas de estudo para a Universidade de Chicago entre 1948 e 1950. Logo depois que eles retornaram, em 1952, foi fundado o Instituto de Matemática Pura e A plicada (IMPA), uma das mais importantes instituições matemáticas brasileiras desde aquela época, onde Nachbin, por um lado, na área da topologia e da análise, e o casal Peixoto, por outro lado, na área dos sistemas dinâmicos, constituíram-se nas principais lideranças científicas pelo menos nos seus primeiros dez anos de funcionamento (SILVA, 2002, 2004).

Como veremos a seguir, Marshall Stone também atuou efetivamente na difusão do MMM na América Latina em geral e no Brasil em particular, contando também com a colaboração de Leopoldo Nachbin.

2 Vinculado à Secretaria de Estado, tratava de assuntos bélicos relacionados com a América Latina. D epois da guerra, passou a chamar O ffice of Inter-American Affairs (OIAA).

Rev. D iálogo Educ., Curitiba, v. 9, n. 26, p. 61-79, jan./ abr. 2009 


\section{Marshall Stone e a matemática moderna no Brasil}

No Brasil, de uma maneira geral, a matemática esteve ligada principalmente à engenharia durante 0 período da história delimitado pela implantação dos primeiros cursos militares, ainda no período colonial, e pela fundação das primeiras universidades com suas respectivas faculdades de filosofia, na primeira metade do século XX, isto é, os matemáticos, os professores de matemática, as pessoas que dominavam um certo tipo de conhecimento matemático, escolar, acadêmico ou superior, geralmente eram engenheiros militares ou civis que se bacharelavam ou se doutoravam nessa ciência ao mesmo tempo em que se formavam engenheiros, pois as escolas politécnicas e as academias militares foram os espaços institucionais que centralizavam a produção e a difusão da matemática nesse período. Evidentemente, existiram exceções à esta regra, como, por exemplo, os padres e freiras que lecionaram matemática nas escolas mantidas por instituições religiosas, inclusive no período colonial, quando os jesuítas predominaram amplamente na educação escolar brasileira (SILVA, 1992; SILVA, 1999; VALENTE,1999; DIAS, 2002). ${ }^{3}$

No Brasil, a primeira tentativa de institucionalização nos programas de ensino secundário das inovações, modificações e transformações ocorridas em diversos aspectos constitutivos da matemática, referidas anteriormente, foi liderada por Euclides Roxo, catedrático de matemática do Colégio Pedro II da capital federal, que implantou em 1929 uma mudança nos programas de ensino matemática inspirada pelas ideias reformistas de Felix Klein. Essa proposta também foi adotada na reforma do ensino secundário do ministro Francisco Campos, em 1931. Todavia, estas modificações sofreram duras contestações por parte de alguns setores ligados ao ensino da matemática. Foi esse ambiente de controvérsias que acompanhou a efetiva inclusão da proposta de Euclides Roxo em outra reforma educacional, aquela empreendida pelo ministro Gustavo Capanema em 1942, quando as ideias reformistas de Felix Klein foram novamente apropriadas na formulação dos programas oficiais para 0 ensino de matemática no Brasil. 0 contexto educacional dessas reformas, em que pese as especificidades brasileiras, foi marcado por embates análogos àqueles ocorridos por ocasião das tentativas de implantação de reformas modernizantes na Alemanha, entre os defensores da tradição humanista clássica vigente, representados principalmente pelos educadores e intelectuais católicos, e os representantes do movimento da educação nova, que defendiam uma modernização do sistema educacional brasileiro (DASSIE, 2001; RO CHA, 2001; BRAGA, 2003).

3 O confronto entre a tradição matemática das escolas de engenharia e a formação de uma novo corpo de matemáticos com formação disciplinar especializada é um dos problemas da institucionalização da matemática enquanto disciplina autônoma em alguns países da América Latina, na primeira metade do século XX. DIAS, 2002; O RTIZ, 2003b.

Rev. Diálogo Educ., Curitiba, v. 9, n. 26, p. 61-79, jan./ abr. 2009 
Interseções teórico-metodológicas entre a história do ensino e a história da matemática

Posteriormente, na década de 1930, com a fundação das primeiras universidades brasileiras, quando também foram fundadas simultaneamente faculdades de Filosofia, unidades universitárias onde começaram a funcionar de forma sistemática e generalizada os primeiros cursos superiores independentes de Matemática, Física, Química, História Natural, História, Geografia, Ciências Sociais, Filosofia e Letras, com o objetivo de formar professores especialistas nessas áreas, que atuariam ora no ensino, ora na pesquisa, as atividades matemáticas passaram por transformações, não apenas ganharam novos espaços institucionais, como também uma nova posição científica e social. Isto é, à medida que 0 matemático deixou de ser identificado com o engenheiro e passou a ter uma identidade profissional própria, independente, também as suas atividades passaram, pouco a pouco, a ser regidas por um novo estatuto científico e adquiriram um novo significado social. Inicialmente em São Paulo e no Rio de Janeiro, nas décadas de 30 e 40, posteriormente em outros centros, como Recife, na década de 50, ocorreu um processo de importação de cientistas estrangeiros que, juntamente com os brasileiros, acabaram por tornar-se agentes destacados de um processo de transferência e apropriação de novos conhecimentos, técnicas, instrumentos, procedimentos e valores éticos (SILVA, 2000, 2002; DIAS, 2002).

Portanto, um aspecto importante a ser destacado é que o processo de institucionalização desses novos padrões de exercício da matemática no Brasil deu-se nos marcos da formação de professores nas faculdades de filosofia, estando portanto associadaa um novo período na profissionalização do magistério secundário no Brasil, em outras palavras, esteve associada à transição da matemática tal como era concebida pelos engenheiros e praticada nas escolas de engenharia, para a matemática tal como concebida por um novo profissional especializado, o matemático, e praticada sob os padrões científicos de uma disciplina específica, a matemática.

Curiosamente, um dos primeiros marcos do processo de atualização e reestruturação do ensino secundário da matemática no Brasil no período pósguerra não se localizou nenhum dos principais centros de pesquisa e do ensino superior. D e fato, o I Congresso Brasileiro de Ensino da Matemática no Secundário foi organizado por Martha Maria de Sousa Dantas, professora de Didática da Matemática da Faculdade de Filosofia (FF) da Universidade da Bahia (UBa), e realizado em Salvador em 1955 (DIAS, 2001).

Martha D antas formou-se na FF em 1948 e, logo depois, no início dos 50, começou a lecionar didática da matemática. Ela dominava dois ou três idiomas estrangeiros, o que lhe permitia acompanhar os debates que eram travados nos periódicos europeus da época e as inovações que começavam a ser implantadas nos países da Europa e nos EUA, onde o ensino da matemática começava a ser atualizado sob a influência dos movimentos referidos anteriormente. Elaborou então um roteiro para a viagem, que se iniciaria na Bélgica, depois passaria pela

Rev. D iálogo Educ., Curitiba, v. 9, n. 26, p. 61-79, jan./ abr. 2009 
Inglaterra, e terminaria na França (DANTAS, 1954). Retornando da Europa, ela buscou o apoio das autoridades universitárias baianas e de professores de outros Estados para realizar o congresso. No seu discurso de abertura, Martha D antas destacou dentre outros aspectos:

Falarei, primeiramente, em linhas gerais, dos objetivos do ensino da Matemática na escola secundária; em seguida, vos perguntarei se, nas condições atuais do ensino, êles se realizam [...]

O fim do ensino científico na escola secundária é duplo: dar ao adolescente os conhecimentos exigidos pela vida moderna e, sobretudo, subordinar o espírito a uma disciplina e a um método, que só a prática das ciências pode proporcionar-lhe e que êle transferirá pelo hábito a todos os atos da sua existência.

Para a consecução dêsses dois objetivos nenhuma outra contribuição se nos apresentará mais valiosa, do que a da matemática, pelo seu alto valor formativo e pelo seu valor utilitário; não menos importante é êste, se considerarmos a sua influência na sistematização e incessante desenvolvimento das outras ciências.

Não é, absolutamente, menosprezar a importância do segundo objetivo, afirmar que a nossa grande preocupação na escola secundária deve ser a de salvaguardar, antes de tudo, a verdadeira formação do espírito. (DANTAS, 1957, p. 257).

Já estavam aí os primeiros sinais anunciando a atualização dos currículos e programas para o ensino da matemática no secundário que viria a ser largamente defendida no Brasil alguns anos mais tarde. Quando ela afirma que a finalidade do ensino científico na escola secundária é tanto propiciar os conhecimentos necessários para a vida moderna, quanto disciplinar o espírito do aluno segundo um método - que seria obviamente um método científico - que formará os hábitos de sua existência, está aí explícito 0 aspecto institucional que caracterizava todas as propostas de renovação dos currículos, desde o primeiro movimento internacional liderado por Klein e Smith.

Como já foi dito por vários autores, a moderna sociedade capitalista, desde a Revolução Industrial da segunda metade do século X IX e principalmente naquela particular conjuntura pós segunda guerra, demandava dos sistemas educacionais não apenas uma mão-de-obra altamente qualificada em conhecimentos científicos e tecnológicos próprios para produzir o crescimento e a expansão da estrutura industrial, mas também altamente disciplinada segundo a

Rev. Diálogo Educ., Curitiba, v. 9, n. 26, p. 61-79, jan./ abr. 2009 
Interseções teórico-metodológicas entre a história do ensino e a história da matemática

racionalidade técnica utilitária fundadora dos padrões de eficiência que vinham sendo implantados em todos os setores da economia capitalista. E os discursos dos protagonistas das reformas do ensino da matemática eram unânimes na afirmação desta relação. (D 'AMBRO SIO, 1987; BÚRIG O, 1989).

D e qualquer sorte, dizia Martha $D$ antas, era preciso mudar, os novos profissionais do ensino da matemática já não se identificavam com os padrões tradicionais e estavam buscando novas referências:

Preocupou-me, sobremodo, a problemática do ensino da matemática. O s programas eram impostos pelo Ministério da Educação, que não consultava os professores. O slivros, elaborados para atender aos programas refletiam os desacertos destes. 0 autoritarismo empolgava a maioria dos mestres que se repetiam, sem cessar, no seu ensino tradicional: nos conteúdos utilizados, no tratamento do aluno, na apresentação da matéria e na sua avaliação. Era preciso mudar. Eu não sabia como mudar e não encontrava publicações que me sugerissem uma mudança. Naquela época os cursos de Metodologia da Matemática eram, por vezes, até ridicularizados e, talvez por isso, não contávamos com literatura apropriada para os mesmos. (DANTAS, 1993).

Portanto, interpreto as manifestações de Martha D antas àquela época e as suas lembranças mais recentes como uma expressão das expectativas dos novos professores de matemática pela constituição de uma nova identidade profissional, fundada na atualização da matemática. O congresso de Salvador foi o primeiro de uma série de cinco eventos que congregaram em número crescente professores de matemática de todas as regiões do país, em Porto Alegre (1957), no Rio de Janeiro (1959), em Belém (1962) e em São José dos Campos (1966).

Já no terceiro congresso, realizado no Rio de Janeiro, em 1959, uma das teses propostas para a comissão de ensino secundário intitulava-se "Aritmética, álgebra, geometria? A unidade da matemática e a delimitação do campo dos seus variados", de autoria do professor Haroldo Lisboa da Cunha, cujas discussões foram relatadas pelo professor Ary Q uintela. Segundo Q uintela, nos encontros já realizados no país, o tema da estruturação da matéria nas diversas séries dos dois ciclos de ensino é dos que mais despertam o interesse entre os professores de matemática, propiciando muitas discussões sobre a sequência, a ordem, a justaposição e a possibilidade de concomitância no ensino da aritmética, da álgebra, da geometria e da trigonometria. D epois de um rápido estudo sobre o significado destes termos em períodos ou autores mais antigos, ele afirma:

Rev. D iálogo Educ., Curitiba, v. 9, n. 26, p. 61-79, jan./ abr. 2009 
Parece-nos muito mais a propósito o que externa Bourbaki, ao tratar da arquitetura das matemáticas, num magnífico apanhado sob o título: "La mathématique ou les mathématiques?". Falam-nos aí, como sabemos, os mais privilegiados cérebros do mundo científico atual! [...]

[...] por si, os vocábulos aritmética, álgebra, geometria, etc., nenhum significado preciso possuem, só se justificando seu uso, em especificações relativas ao ensino, se estabelecida, preliminarmente, conceituação adequada. Ressalta-se, desse modo, a magnífica unidade do pensamento matemático que, mesmo ou principalmente no curso secundário, parece-nos dever ser comprovada, a cada passo, aos nossos alunos.

Ora, a referência - pelo menos sistemática - a tais termos, em programas, recomendações, instruções, ou o que mais seja, assim o julgamos, só poderá afastá-los da idéia dessa unidade!

Paladino houve, que dedicasse quase que sua vida inteira a esse tema: homem tão célebre na pesquisa, como na divulgação da ciência matemática e de suas normas metodológicas; homem cuja obra foi deliberadamente dissolvida por questões de ordem racial, e que, por isso, é muitas vezes desconhecido e combatido, aqui e alhures. Queremos nos referir a Felix Klein [...]. (CONG RESSO BRASILEIRO DO ENSINO DA MATEMÁTICA, 1959, p. 15).

Temos aqui, pois, explicitamente, todos os elementos necessários para identificar a presença da temática da atualização dos programas escolares de matemáticajá nas discussões do congresso do Rio de Janeiro em 1959. Em primeiro lugar, a unificação da matemática foi uma das principais inovações que marcaram a diferença entre os novos padrões instituídos a partir do século X IX e as tradições antecedentes. Se, por um lado, a reivindicação para que tal unidade fosse aceita como fato e "comprovada" para os alunos do nível secundário indica um comprometimento com esta referência, por outro lado, a dúvida sobre a utilização da tradicional divisão das antigas matemáticas nos currículos e programas do ensino secundário seria um indicador inequívoco de que a institucionalização dessa referência ainda não se havia completado.

Além disso, os destaques dados à Bourbaki e à Felix Klein - e a forma como estes destaques foram feitos - indicam também não apenas a familiaridade que 0 relator, professor Ary Q uintela, conhecido autor de livros

Rev. Diálogo Educ., Curitiba, v. 9, n. 26, p. 61-79, jan./ abr. 2009 
Interseções teórico-metodológicas entre a história do ensino e a história da matemática

didáticos, tinha com estas referências fundamentais dos dois movimentos internacionais mencionados anteriormente, mas também como essas referências seriam possivelmente familiares ao professores de matemática presentes no eventos.

O congresso de São José dos Campos, realizado em 1966, foi absolutamente dominado pelo $\mathrm{MMM}$, tanto na sua concepção, organização e atividades realizadas, quanto na participação dos conferencistas convidados. Com efeito, este evento foi organizado pelo G rupo de Estudos do Ensino da Matemática - GEEM, presidido por O svaldo Sangiorgi, que foi também o presidente da comissão organizadora do evento, um dos principais líderes entre os professores de matemática brasileiros e dos mais ativos divulgadores do MMM no Brasil. (VALENTE, 2007)

Esse evento contou com a participação de Marshall Stone, presidente da Comissão Interamericana de Educação Matemática (CIAEM); de G eorge Papy, presidente do Centro Belga de Pedagogia da Matemática; membro da Comissão Internacional do Ensino da Matemática (ICMI); além de Hector Merklen, da Universidade de Montevidéu e do Programa Interamericano para 0 Desenvolvimento do Ensino da Matemática.

A presença destes matemáticos estrangeiros não era uma novidade, pois o Comitê CIAEM foi criado em 1961, por iniciativa do próprio Stone, que pretendia, segundo lembrança de Ubiratan D 'Ambrosio, (2008):

[...] a intenção de regionalizar sobre a Educação Matemática e, ao mesmo tempo, dar uma maior presença dos Estados Unidos na América Latina. A UNESCO havia aberto uma Oficina Regional de Ciências e Tecnologia para a América Latina e Caribe (ORCTALC), em Montevidéu, ea O rganização dos Estados Americanos (OEA) procurava expandir seus programas.

Para alcançar esses objetivos, o CIAEM promoveu duas conferências interamericanas sobre educação matemática, a primeira em Bogotá, em 1961, e a segunda em Lima, em 1965. Nos anais destes dois eventos estão registradas as participações dos representantes brasileiros, dentre os quais, Leopoldo Nachbin, membro da comissão organizadora internacional dos dois eventos; e Martha Dantas, conferencista do segundo evento.

\section{H istória da matemática e do seu ensino: aproximações}

Volto, portanto, aos motivos que me levaram à essa digressão histórica: mostrar que a aproximação da história do ensino da matemática com a história da matemática não é arbitrária ou a priori no caso da pesquisa sobre os

Rev. D iálogo Educ., Curitiba, v. 9, n. 26, p. 61-79, jan./ abr. 2009 
movimentos internacionais de renovação dos programas de ensino secundário de matemática, em particular, no caso do segundo movimento, conhecido como MMM. Mostramos que um dos seus protagonistas, o matemático Marshall Stone, foi também protagonista da ação estratégica de expansão da influência científicomatemática americana no período do pós-guerra, no contexto da Guerra Fria.

Assim, temos por um lado que o MMM pode ser analisado historicamente como uma série de iniciativas para reforma do ensino escolar da matemática que congregou autoridades educacionais, matemáticos e educadores de diversos países, notadamente nos EUA e na Europa, mas também na América Latina, entre os anos 1950 e 1980. Essas iniciativas associaram-se de alguma forma e numa certa medida aos interesses corporativos e profissionais dos matemáticos, liderados por instituições como a União Internacional de Matemáticos - Comitê Internacional para a Instrução Matemática, de transpor para os currículos escolares a matemática moderna, isto é, certas referências matemáticas "modernas" institucionalizadas entre os matemáticos desde o século X IX, que estavam ausentes dos currículos em prejuízo desses interesses.

Todavia, por outro lado, inspirando-se em Chartier (1995), a análise histórica das tentativas de institucionalização de certos padrões culturais, em atendimento a interesses de grupos maiores ou menores, detentores de um certo tipo de poder controlador ou disciplinador, num certo nível, não será completa se não contemplar as formas de apropriação desses padrões pelos grupos, minoritários ou não, submetidos de alguma forma e num certo nível àquele poder disciplinador ou controlador. Lembrando agora D e Certeau, para evitar a tensão entre a dependência e a autonomia na análise das relações culturais entre grupos dominantes e dominados, entre os que detêm e os que não detêm um certo poder institucionalizado ou institucionalizador, é preciso analisar historicamente as táticas utilizadas por estes últimos, os seus "modos de fazer", suas práticas quotidianas, suas formas de consumo cultural, pensadas como táticas produtoras de sentido, possivelmente estranho àquele definidos pelos primeiros (apud CHARTIER, 1995, p. 7).

Além disso, resta considerar pelo menos que o MMM também pode ser analisado historicamente como um dos ramos matemáticos da rede internacional de comércio científico retomada e incentivada por organismos como a Unesco, a OEA e a O ECE após a Segunda G uerra Mundial no contexto da Guerra Fria, segundo os interesses, razões e motivos expansionistas e estratégicos do bloco capitalista encabeçado pelos EUA. Associada à esta dimensão, estaria também a análise do MMM como uma empresa da indústria cultural que se consolidou e se expandiu no período pós Segunda Guerra, como um dos aspectos da expansão do capitalismo ocidental, liderado pelo imperialismo norte-americano, em outras palavras, a matemática moderna

Rev. Diálogo Educ., Curitiba, v. 9, n. 26, p. 61-79, jan./ abr. 2009 
Interseções teórico-metodológicas entre a história do ensino e a história da matemática

analisada como um produto da indústria cultural, como um produto da indústria editorial dos livros didáticos, que ampliou-se, multiplicou-se enormemente, acompanhando a expansão e a universalização dos sistemas escolares de ensino, em todos os níveis, em quase todos os países do globo terrestre.

Essas são apenas três importantes dimensões que podem ser destacadas na análise histórica do MMM. A abordagem da história das ciências em particular, da matemática - que estuda os processos de institucionalização internacional das ciências modernas de raízes europeias nos contextos socioeconômicos das diversas regiões, das diversas localidades não europeias, destacando diversos tipos de atores, instituições e processos, particularmente as escolas e seus professores, relacionando-os aos processos políticos e econômicos de (des)colonização e expansão capitalista (VE SSURI, 1994), daria conta de pelos menos dois dos aspectos destacados anteriormente. Já a abordagem que toma a cultura escolar como objeto histórico, buscando as formas locais de apropriação da matemática moderna em escolas, as representações e práticas dos atores escolares, promete resultados satisfatórios sobre um outro aspecto referido.

Essas abordagens tomadas isoladamente resultam numa visão reduzida do MMM, razão pela qual devem ser articuladas num quadro teóricometodológico apropriado que permita uma visão mais rica, ao mesmo tempo ampliada e aprofundada do mesmo. A este respeito, quero destacar, por um lado, que alguns trabalhos publicados sobre o MMM (VALENTE, 2006; OLIVEIRA, 2006) têm adotado a descrição densa e a definição de cultura de Clifford G eertz ao lado da definição de cultura escolar de D ominique Julia, ao mesmo tempo em que adotam também os conceitos de representação, prática e apropriação de Roger Chartier. Por outro lado, lembrarei a seguir a crítica que Chartier dirige aos historiadores que tomam a cultura como objeto de pesquisa, mas o fazem tomando também 0 conceito de cultura e 0 método etnográfico de Clifford G eertz como referências teórico-metodológicas.

De fato, Chartier (1985) teceu críticas à utilização historiográfica dos conceitos de descrição densa e de cultura de $\mathrm{G}$ eertz na resenha que escreveu sobre o livro de $\mathrm{D}$ arnton (1984). Isto é, depois de comentar que $\mathrm{D}$ arnton e $\mathrm{G}$ eertz trabalharam juntos durante um certo período em Princeton, Chartier questionou em que medida o conceito de cultura de $\mathrm{G}$ eertz seria utilizável por um historiador e qual atitude diante dos textos decorreria de tal definição. Mais adiante, referindose às descrições densas, Chartier questiona se seria legítimo considerar ações executadas pelos personagens históricos como textos.

Segundo Chartier (1985, p. 688), a história cultural deve se dedicar a pesquisar as diferentes maneiras pelas quais grupos ou indivíduos usam, interpretam e se apropriam dos motivos intelectuais ou das formas culturais que dividem com os outros:

Rev. D iálogo Educ., Curitiba, v. 9, n. 26, p. 61-79, jan./ abr. 2009 
Daí a complexidade das mudanças nas tarefas dos historiadores para focar sua atenção nas trajetórias individuais, para revogar ou duvidar da separação canônica entre cultura popular e escolarizada, e para tentar reconstruir as práticas com base nas representações dadas das mesmas e dos objetos manipulados nas mesmas.

Em particular, para uma pesquisa histórica que tem como objeto uma cultura matemática, é interessante chamar a atenção para suas considerações sobre a relação entre símbolo e significado:

[...] os seus significados [do símbolo] são instáveis, móveis e equívocos. Não são sempre facilmente decifráveis e nem sempre bem decifrados. Assim, parece difícil postular que, em um dado momento e em um dado lugar, uma dada cultura [...] é organizada de acordo com um repertório simbólico cujos elementos estão documentados em várias datas [...] e em múltiplos lugares. (CHARTIER, 1985, p. 690).

São estas considerações que fundamentam a crítica de Chartier à abordagem da cultura de G eertz, na medida em que este último postula que os símbolos estão organizados em um sistema, na medida em que supõe de alguma forma coerência e interdependência entre os símbolos, que pressupõe a existência de um universo simbólico unificado e compartilhado. Segundo Chartier, tal sistema e unidade parecem duvidosos dadas as clivagens sociais, as fragmentações e diferenciações sociais por idade, sexo, raça, prestígio, profissão, religião, educação etc. etc. Portanto, ele conclui, o uso metafórico do vocabulário da linguística - ler o mundo como um texto - é arriscado (HUNT, 1992).

Na minha opinião, neste momento em que estamos tentando tirar proveito teórico e metodológico da aproximação entre história do ensino da matemática e história da matemática, Chartier pode nos ser útil efetivamente com uma grande inspiração: diante da sua proposta de "revogar ou duvidar da separação canônica entre cultura popular e escolarizada", podemos tomá-la metaforicamente e pensar nas condições em que poderíamos "revogar ou duvidar da separação canônica entre cultura científica e escolarizada" (CHERVEL, 1990; PAIS, 2001; TARDIF, 2000; VALENTE, 2003).

Ora, se na análise histórica do MMM constatamos que há efetivamente a conjugação de uma série de interesses, científicos, profissionais, educativos, estratégicos, diplomáticos e comerciais, dentre outros, que sustentam

Rev. Diálogo Educ., Curitiba, v. 9, n. 26, p. 61-79, jan./ abr. 2009 
Interseções teórico-metodológicas entre a história do ensino e a história da matemática

um movimento internacional de institucionalização universal da "matemática moderna" nos currículos e programas escolares de ensino primário e secundário, ao longo das décadas de 1950 e 1960, cabe recorrer às ponderações de Chartier $(1985$, p. 3) a respeito do "verdadeiro problema" da história cultural: "considerar, para cada época, como se elaboram as relações complexas entre formas impostas, mais ou menos constrangedoras e imperativas, e identidades afirmadas, mais ou menos desenvolvidas e reprimidas."

Em outras palavras, a força com a qual modelos culturais - como 0 MMM - impõem sentido, não anula o espaço próprio da sua recepção, que pode ser resistente, matreira ou rebelde:

Existe um espaço entre a norma e o vivido, entre a injunção e a prática, entre 0 sentido visado e 0 sentido produzido, um espaço onde podem insinuar-se reformulações e deturpações. Nem a cultura de massa do nosso tempo, nem a culturaimposta pelos antigos poderes foram capazes de reduzir as identidades singulares ou as práticas enraizadas que lhes resistiam. 0 que mudou, evidentemente, foi a maneira pela qual essas identidades puderam se enunciar e se afirmar, fazendo uso inclusive dos próprios meios destinados a aniquilá-las. Reconhecer esta mutação incontestável não significa romper as continuidades culturais que atravessam os três séculos da idade moderna, nem tampouco decidir que, após o corte da metade do século XVII, não há mais lugar para gestos e pensamentos diferentes daqueles que os homens da Igreja, os servidores do Estado ou as elites letradas pretendiam inculcar em todos. (CHARTIER, 1985, p. 4).

Em suma, "revogar ou duvidar da separação canônica entre cultura científica e escolarizada" não implica necessariamente em supor que a cultura científica determine a forma e o conteúdo da cultura escolar. Pelo contrário, a constatação de que houve efetivamente interesses de grupos sociais, interesses científicos e profissionais; interesses de classe, econômicos, comerciais, estratégicos, diplomáticos e militares, na institucionalização da matemática moderna nas escolas, pode se constituir efetivamente no ponto de partida para a pesquisa sobre as formas de resistência e de transformação que caracterizaram no processo de circulação cultural as formas próprias de apropriação por parte dos professores e demais atores do espaço social-cultural das escolas primárias e secundárias do Brasil e de Portugal.

Rev. D iálogo Educ., Curitiba, v. 9, n. 26, p. 61-79, jan./ abr. 2009 
Dias, A. L. M.

\section{REFERÊNCIAS}

BALDINO, R. R. A ética de uma definição circular de número real. Bolema, v. 10, n. 9, p. 31-52, 1994.

BELHOSTE, B.; GISPERT, H.; HULIN, N. Les sciences au lycée. Paris: INRP/ Vuibert, 1996.

BO S, Henk J. M.; MEHRTENS, H.; SCHNEIDER, I. (Ed.). Social history of nineteenth-century mathematics. Boston: Birkhäuser, 1981.

BRAGA, C. Felix Klein e os princípios do movimento modernizador do ensino da matemática secundária do início do século XX. In:

0 processo inicial de disciplinarização de função na matemática do ensino secundário brasileiro. 2003. Dissertação (Mestrado em Educação Matemática) - Pontifícia Universidade Católica São Paulo, São Paulo, 2003.

. 0 processo inicial de disciplinarização de função na matemática do ensino secundário brasileiro. 2003. D issertação (Mestrado em Educação Matemática) - Pontifícia Universidade Católica de São Paulo, São Paulo, 2003.

BÚRIG O, E. Z. Movimento da matemática moderna no Brasil: estudo da ação e do pensamentos de educadores matemáticos nos anos 60 f. 1989. D issertação (Mestrado em Educação) - Uiniversidade Federal do Rio Grande do Sul, Porto Alegre, 1989.

CHARTIER, R. "Cultura popular": revisitando um conceito historiográfico. Estudos H istóricos, v. 8, n. 16, p. 179-192, 1995.

. Text, symbols, and frenchness. Journal of Modern H istory, v. $\overline{5} \overline{7}, \bar{n} .4$, p. 682-695, 1985.

CHERVEL, A. História das disciplinas escolares: reflexões sobre um campo de pesquisa. Teoria \& Educação, n. 2, p. 177-229, 1990.

CONGRESSO BRASILEIRO DO ENSINO DA MATEMÁTICA, 3. 1959. Rio de Janeiro. Anais... Rio de Janeiro: CAD E S-MEC, 1959. p. 15.

D'AMBRO SIO, B. S. The dynamics and consequences of the modern mathematics reform movement for Brazilian mathematics education. 1987. Tese (D outoramento em Educação) - Indiana University, Indiana, 1987.

D 'AMBROSIO, U. Reminicências pessoais da minha atuação enquanto presidente do CIAEM. Disponível em: <www.vello.sites.uol.com.br/ remi.htm>. Acesso em: 13 fev. 2009.

Rev. Diálogo Educ., Curitiba, v. 9, n. 26, p. 61-79, jan./ abr. 2009 
Interseções teórico-metodológicas entre a história do ensino e a história da matemática

DANTAS, M. M. de S. O ensino da matemática na Bélgica, Inglaterra e França: relatório de estudos realizados na Europa em 1953. Arquivos da Universidade da Bahia (Faculdade de Filosofia), v. 3, p. 133-156, 1954.

. Discurso de abertura. In: CONGRESSO NACIONAL DE E'N S̄INO DA MATEMÁTICA NO CURSO SECUNDÁRIO, 1., Salvador, 1955. Anais... Salvador: Faculdade de Filosofia, Universidade da Bahia, 1957. p. 255-263.

D epoimento. Cadernos do IFUFBA, ano 9, v. 6, n. 1- 2, p. $\overline{1} \overline{1}-\overline{36}, 1993$.

DARNTON, R. The great cat massacre and other episodes in French cultural history. New York: Basic Books, 1984.

DASSIE , B. A. A matemática do curso secundário na reforma G ustavo Capanema. 2001. Dissertação (Mestrado em Matemática) - Pontifícia Universidade Católica do Rio de Janeiro, Rio de Janeiro, 2001

DIAS, A. L. M. As fundadoras do Instituto de Matemática e Física da Universidade da Bahia. História, Ciências, Saúde - Manguinhos, v. 7, n. 3, p. 653-674, 2001.

. Engenheiros, mulheres, matemáticos: interesses e disputas nā profissionalização da matemática na Bahia (1896-1968). 2002. Tese (História Social) - Universidade de São Paulo, São Paulo, 2002.

FELIX, L. Aperçu historique sur la CIEAEM (1950-1984). Bordeaux: IREM, 1986.

G RAY, J. J. A nxiety and abstraction in nineteenth-century mathematics. Science in Context, v. 17, n. 1/ 2, p. 23-47, 2004.

GUIMARÃE S, H. M. Por uma matemática nova nas escolas secundárias: perspectivas e orientações curriculares da matemática moderna. In: MATOS, J. M.; VALENTE, W. R. (O rg.). A matemática moderna nas escolas do Brasil e de Portugal: primeiros estudos. São Paulo: GHEMAT, 2007. p. 21-45.

HUNT, L. A nova histónia cultural. São Paulo: Martins Fontes, 1992.

MATOS, J. M.; VALENTE, W. R. (Org.). A matemática moderna nas escolas do Brasil e de Portugal: primeiros estudos. São Paulo: GHEMAT, 2007.

O'CONNOR, J. J.; ROBERTSO N, E. F. Marshall Harvey Stone. Disponível em: <http:/ / www-history.mcs.st-andrews.ac.uk/ Biographies/ Stone.html>. Acesso em: 13 fev. 2009.

Rev. D iálogo Educ., Curitiba, v. 9, n. 26, p. 61-79, jan./ abr. 2009 
Dias, A. L. M.

OECE. Mathématiques nouvelles. Paris: OE CE, 1961.

OLIVEIRA, M. C. A. de. Professores de matemática ao tempo do Movimento da Matemática Moderna: perspectivas de pesquisa. Revista Diálogo E ducacional, v. 6, n. 18, p. 79-89, 2006.

ORTIZ, E. L. El viaje de Birkhoff a la Argentina y la política interamericana de Roosevelt. Sabery Tiempo, v. 4, n. 16, p. 21-70, 2003 a.

. La política interamericana de Roosevelt: G eorge D. Birkhoff y Tāinclusión de A mérica Latina en las redes matemáticas internacionales (Parte I). Saber y Tiempo, v. 4, n. 15, p. 53-111, 2003b.

PAIS, L. C. Didática da matemática: uma análise da influência francesa. Belo Horizonte: Autêntica, 2001.

REVISTA DIÁLOGO EDUCACIONAL. História da Educação Matemática. Curitiba, v. 6, n. 18, 2006.

RO CHA, J. L. da. A matemática do curso secundário na reforma Francisco Campos. 2001. Dissertação (Mestrado em Matemática) Pontifícia Universidade Católica do Rio de Janeiro, Rio de Janeiro, 2001 ROWE, D. E. Making mathematics in an oral culture: Göttingen in the era of Klein and Hilbert. Science in Context, v. 17, n. 1/ 2, p. 85-129, 2004.

SCHUBRING, G. 0 primeiro movimento internacional de reforma curricular em matemática e o papel da Alemanha: um estudo de caso na transmissão de conceitos. Zetetiké, v. 7, n. 11, p. 29-50, 1999.

. Rupturas no estatuto matemático dos números negativos. Boletim GEPE M, n. 37, p. 51-65, 2000.

. Rupturas no estatuto matemático dos números negativos. Boletim GEPEM, n. 38, p. 73-93, 2001.

SILVA, C. M. S. da. A matemática positivista e sua difusão no Brasil. Vitória: ED UFE S, 1999.

. A Faculdade de Filosofia, Ciências e Letras da USP e a formação de professores de matemática. In: REUNIÃO ANUAL DA ANPEd, 23., Anais... Caxambu:ANPEd, 2000. D isponível em: <www.anped.br>. Acesso em: 13 fev. 2009

. A Formação de professores e pesquisadores de matemática na Faculdada Nacional de Filosofia. Cadernos de Pesquisa, n. 117, p. 103-126, nov. 2002.

Rev. Diálogo Educ., Curitiba, v. 9, n. 26, p. 61-79, jan./ abr. 2009 
Interseções teórico-metodológicas entre a história do ensino e a história da matemática

. A construção de um instituto de pesquisas matemáticas nos trópicos: 0 IMPA. Revista Brasileira de História da Matemática, v. 4, n. 7, p. 37-67, 2004.

SILVA, C. P. da. A matemática no Brasil: uma história do seu desenvolvimento. Curitiba: Ed. da UFPR, 1992.

STONE, M. H. Reminiscences of mathematics at Chicago. In: AMERICAN MATHEMATICAL SOCIETY. A century of mathematics in America II. Providence: American Mathematical Society, 1989. p. 183-190.

TARDIF, M. Saberes profissionais dos professores e conhecimentos universitários: elementos para uma epistemologia da prática profissional dos professores e suas consequências em relação à formação para 0 magistério. Revista Brasileira de Educação, n. 13, p. 5-24, 2000.

VALENTE, W. R. Uma história da matemática escolar no Brasil (1730-1930). São Paulo: Annablume, 1999.

. Saber científico, saber escolar e suas relações: elementos para reflexẫo sobre a didática . Revista Diálogo Educacional, v. 4, n. 10, p. 57-67, 2003.

. A matemática moderna nas escolas do Brasil: um tema para estudos históricos comparativos. Revista Diálogo Educacional, v. 6, n. 18, p. 19-34, 2006.

. O svaldo Sangiorgi e o movimento da matemática moderna no Brasil. In: SEMINÁRIO TEMÁTICO: A MATEMÁTICA MODERNA NAS ESCOLAS DO BRASIL E DE PORTUGAL, 4., 2007. Almada. Anais. Lisboa, 2007.

VESSURI, H. The institutionalisation process. In: SALOMON, JeanJacques; SAG ASTI, Francisco R.; SACHS-JEANTET, Céline. (Ed.). The uncertain quest: science, technology and development. Tokyo: The United Nations University, 1994. D isponível em: <http:/ / www.unu.edu/ unupress/ unupbooks/ uu09ue/ uu09ue00.htm>. Acesso em: 13 fev. 2009.

Recebido: 12/ 09/ 2008

Received: 09/ 12/ 2008

Aprovado: 20/ 11/ 2008

A pproved: $11 / 20 / 2008$

Rev. D iálogo Educ., Curitiba, v. 9, n. 26, p. 61-79, jan./ abr. 2009 